\title{
A construção coletiva do conhecimento e a pesquisa-ação participativa: compromissos e desafios
}

\author{
Marília Freitas de Campos Tozoni-Reis ${ }^{1}$ \\ Instituto de Biociências - UNESP - Botucatu, SP
}

resumo: As pesquisas participativas, que têm perspectivas sócio-históricas e, portanto, de superação da tradição empirista da pesquisa científica, vêm se consolidando como metodologia em educação ambiental exigindo reflexões e avaliações. Este artigo apresenta as análises de dezenove projetos de iniciação científica com a pesquisa-ação-participativa em educação ambiental orientados pela autora. As categorias de análise apresentadas são: a mediação do educador no processo grupal; os temas ambientais como geradores de um processo educativo; a participação; e, por último, as possibilidades e limites da pesquisa-ação-participativa em educação ambiental com crianças. As análises têm como objetivo contribuir para a consolidação da pesquisa-ação-participativa em educação ambiental como forma metodológica de produzir conhecimentos pedagógicos e, ao mesmo tempo, proporcionar oportunidades para que, na formação inicial dos educadores ambientais, a universidade realize uma relação intensa e competente com a comunidade, respondendo às suas necessidades de formação humana.

palavras-chave: Pesquisa-ação participativa, crianças, formação de educadores ambientais.

abstract: Participative research, which is progressively being accepted in the methodology of human sciences, brings a socio-historical perspective that helps to overcome the empiricist tradition in scientific methodology, opening new discussions. Departing from such necessity, this article presents an analysis of nineteen projects of scientific research on participative-active-research supervised by the author. The analytic categories here presented are: the group process triggered by the methodology; the environmental themes generating an educative process; the participation in the activities of investigation and educative action; and the possibilities and limits of participative-active-research with children. The analyses presented have the objectives of contributing to the

\footnotetext{
1 e-mail:mariliaedu@ibb.unesp.br

Financiamento: FAPESP
} 
consolidation of participative-active research in environmental education, as a methodological form to produce pedagogical knowledge, and at the same time offer an opportunity for the public university to develop an intense and competent relationship with the community.

keywords: Participative Action Research, Children, Education of Environmental Educators.

\section{Introdução}

A formação de sujeitos ambientalmente responsáveis, comprometidos com a construção de sociedades sustentáveis, fundamento filosófico-político e teórico-metodológico da educação ambiental, é uma ação intencional, um processo educacional intencional e, portanto, necessita de sistematização pedagógica e metodológica. A educação ambiental é educação, é formação humana, é educação em suas várias dimensões, é, portanto, um processo de apropriação, pelos sujeitos, da humanidade construída histórica e coletivamente pela própria humanidade (SAVIANI, 1994). Dessa forma, o processo educativo ambiental diz respeito à relação entre cidadania e ambiente, às formas históricas com que a humanidade se relaciona com o ambiente, assim como às formas históricas das relações entre os sujeitos e destes com o ambiente, priorizando a necessidade de participação política dos sujeitos sociais empenhados na transformação social. Essa participação política no campo educativo é resultado da apropriação crítica e reflexiva dos conhecimentos sobre o ambiente que poderá garantir os espaços de construção e (re)elaboração de valores éticos para uma relação responsável dos sujeitos entre si e desses com o ambiente.

A apropriação crítica de conhecimentos sobre o ambiente realiza-se a partir de uma concepção ampliada do mesmo, uma concepção complexa que considera seu caráter social, histórico e dinâmico, que supera a concepção biológica e o entende como síntese de múltiplas determinações. Nesse sentido, Leff (2001, p. 224) afirma que "o ambiente não é pois o meio que circunda as espécies e as populações biológicas, é uma categoria sociológica (e não biológica), 
relativa a uma racionalidade social, configurada por comportamentos, valores e saberes, como também novos potenciais produtivos". A argumentação desse autor coloca o ambiente como tema "fundante" do processo de construção do saber ambiental, não um tema a ser "dissecado" nesse processo, mas um tema a ser problematizado, gerando ações de produção de conhecimento voltados, radicalmente, para a construção de uma nova racionalidade, que pode ser entendida como uma nova ciência, uma racionalidade social ancorada nos princípios de sustentabilidade, justiça e democracia. Ele completa:

Esta forma de conhecimento está de acordo com um processo de apropriação subjetiva e coletiva, capaz de induzir um processo participativo de tomada de decisões, onde a população deixe de ser controlada (alienada, manipulada) pelos mecanismos cegos do mercado e por leis científicas governadas por processos automáticos, acima de sua consciência e seu entendimento. A racionalidade ambiental orienta a reconstrução de conhecimentos, saberes e práticas, a partir da crítica da racionalidade formal e instrumental da civilização moderna (LEFF, 2001, p. 233-234).

Essas idéias tecem uma proposta de educação ambiental para a sustentabilidade, capaz de atuar na formação de sujeitos sociais críticos, participativos, que se pautem pela construção de uma sociedade em que a sustentabilidade seja entendida também como democracia, eqüidade, justiça, autonomia e emancipação. Isso significa superar a idéia, muito presente nas propostas de educação ambiental, de que a educação ambiental tem como objetivo a "mudança de comportamento" dos sujeitos em busca de comportamentos considerados ambientalmente corretos, configurando-se, como nos ensina Brügger (1994), num adestramento ambiental. Nesse sentido, precisamos também buscar a superação do caráter moralista e moralizante que temos observado em algumas ações educativas ambientais (LOUREIRO, 2004) para a construção da educação ambiental crítica e emancipatória.

Considerando que a educação ambiental é um processo de formação humana, amplo, contínuo e complexo, podemos pensar em projetos para idosos, adultos, jovens e crianças, assim como em 
propostas em variados espaços educativos onde vivem, real e concretamente, os sujeitos sociais. Se o processo intencional de formação humana que diz respeito à educação ambiental é tão diverso, também exige diversidade a pesquisa em educação ambiental. Se considerarmos, como nos ensina Santos (1989), que a pesquisa é a prática social de conhecimento, temos que pensar formas alternativas e criativas de produzir conhecimentos que tenham a relevância científica e social necessária para realizar a relação entre teoria e prática na produção de saberes ambientais significativos para a construção de sociedades socialmente justas e ecologicamente equilibradas, sociedades sustentáveis.

Com essas preocupações, entendemos a produção de conhecimentos no mundo acadêmico. A universidade, em busca da superação da crise de legitimidade que vem sofrendo (SANTOS, 2004), pode desenvolver estratégias acadêmico-científicas que a obriguem a problematizar a demanda social a ela colocada, isto é, interpretar as necessidades da sociedade de forma a identificar nelas sua origem e qualidade social, história e concreta. Entre essas necessidades, Buarque (1994) redefine as tradicionais funções de ensino, pesquisa e extensão, propondo a revalorização do ensino, a "redescoberta" da importância do ensino por parte dos professores - hoje muito mais pesquisadores do que educadores. Além disso, propõe que a investigação científica busque caminhos para tornar-se livre e ao mesmo tempo comprometida socialmente; propõe que a prática da extensão seja valorizada a ponto de, institucionalizada, constituir-se articuladora entre o ensino e a pesquisa; propõe ainda que a democracia torne-se um valor presente na convivência no interior da universidade e em sua relação com a sociedade; e, que a universidade empreenda esforços para a implantação efetiva de uma política cultural integrada ao processo educativo.

Assim, para a formação dos novos sujeitos, as atividades universitárias podem incorporar a idéia de "ambientalização" como eixo temático e a democracia como valor nas ações educativas. Em busca da ambientalização das atividades universitárias, da articulação radical entre ensino, pesquisa e extensão, da busca da concretização da democracia como um valor e da integração de um processo de desenvolvimento cultural socialmente comprometido, temos realizado nossas atividades 
cotidianas. Entre aquelas potencialmente mais integradoras dessas dimensões da vida acadêmica, a orientação de trabalhos de iniciação científica tem se mostrado profícua. Ao trazer para a pesquisa em educação ambiental na iniciação científica a metodologia da pesquisaação participativa, vivenciamos a possibilidade de inserir na formação inicial dos educadores ambientais uma experiência acadêmica alternativa, que integrou teoria e prática, ensino, pesquisa e extensão, áreas de conhecimento e universidade/comunidade.

$\mathrm{O}$ estudo aqui apresentado tem como objetivo analisar, na perspectiva dessa integração, os trabalhos de conclusão que orientei no curso de graduação em Ciências Biológicas, modalidade Licenciatura, nos últimos cinco anos. Todos os trabalhos analisados tiveram como assunto a educação ambiental e como metodologia a pesquisa-ação participativa. Dos 33 trabalhos de conclusão de curso, monografias de iniciação científica que orientei de 2001 a 2005, todos sobre educação ambiental, 19 (58\%) foram realizados com a metodologia da pesquisaação participativa. Dos 19 trabalhos, 5 realizaram-se com crianças préescolares, 4 com crianças cursando as séries iniciais $\left(1^{\mathrm{a}}\right.$ a $\left.4^{\mathrm{a}}\right)$ do ensino fundamental, 5 com pré-adolescentes e adolescentes cursando a segunda etapa do ensino fundamental $\left(5^{\mathrm{a}}\right.$ a $\left.8^{\mathrm{a}}\right), 4$ com jovens do ensino médio e 1 com idosos.

Os resultados obtidos nesses diferentes projetos serão aqui apresentados segundo categorias de análises que se constituem num recorte metodológico para melhor aprofundamento e compreensão: o processo grupal, os temas ambientais trabalhados, a participação dos envolvidos e a dimensão investigativa da pesquisa-ação participativa. Por último, como conclusão, são apresentadas reflexões acerca da relevância, social e científica, da pesquisa-ação participativa em educação ambiental com crianças.

\section{O papel da mediação do educador no processo grupal}

Em todos os projetos realizados, encontramos como ponto fundamental para análise um processo particular que a metodologia da 
pesquisa-ação participativa desencadeia: o processo grupal. Vejamos primeiro o contexto em que foram realizados os estudos.

Os cinco estudos em que as crianças pré-escolares foram, muito mais do que "objetos" de estudos investigativos, parceiros de um processo de investigação e ação foram desenvolvidos na escola, isto é, nas instituições de educação infantil. Quatro dos estudos foram realizados em escolas de educação infantil municipais - as EMEIs - e um na escola de educação infantil que atende a filhos de professores, funcionários e alunos da UNESP-Lageado - CCI. O grau de autonomia que é possível às crianças dessa idade determinou sua realização durante o horário escolar, ou seja, todos esses projetos aconteceram como educação ambiental formal, embora não tenham sido coordenados pelas professoras das crianças, mas pelas alunas-pesquisadoraseducadoras. Isso indica uma das principais características dos projetos: pesquisadoras e crianças construíram uma relação própria, diferente da relação que estas vêm vivenciando com suas professoras.

Dos quatro projetos realizados com crianças das séries iniciais do ensino fundamental, $1^{a}$ a $4^{a}$, nenhum deles deu-se na escola, em horário escolar, vinculado às atividades formais do currículo. Todos foram realizados em período oposto ao escolar, isto é, as crianças foram convidadas, nas escolas, a participar dos projetos e aderiram voluntariamente. Todos eles, em épocas diferentes, realizaram suas reuniões na Associação de Moradores do Bairro com crianças de diferentes idades, alunas de uma mesma escola pública municipal do bairro. O espaço comunitário da Associação e a autonomia de condução do projeto por parte das alunas-pesquisadoras-educadoras foram dois dos seus mais importantes componentes.

Dos cinco projetos realizados com pré-adolescentes e adolescentes, escolares da segunda etapa do ensino fundamental $-5^{\mathrm{a}}$ a $8^{a}$ séries -, todos ocorreram em horário alternativo ao escolar e nas dependências da escola. Três deles aconteceram na mesma escola de um bairro popular da cidade, o mesmo dos projetos com crianças de $1^{\mathrm{a}}$ a $4^{\text {a }}$ séries.

Dos quatro projetos realizados com jovens do ensino médio, em horário alternativo ao escolar, dois aconteceram na escola. Nos dois 
outros, as reuniões aconteceram numa sala cedida pela Prefeitura num ginásio de esportes da cidade. A idade dos jovens, bastante próxima à dos alunos-pesquisadores-educadores, é uma das características dos trabalhos que se destaca na análise do vivenciado. Um projeto foi desenvolvido com idosos, reunidos no SESI, localizado num bairro popular da cidade.

Em todos os projetos, pudemos observar a realização do que conhecemos por processo grupal. Os grupos não foram tratados como tais apenas porque se encontraram num mesmo espaço; a convivência não foi para nós em nenhum momento uma situação dada, mas construída pelo próprio processo de pesquisa e ação educativa, dependendo, é claro, das condições objetivas de sua realização.

Os processos grupais formados pelas parcerias que se estabeleceram revelaram temas importantes de análise, como autonomia, relação professor-aluno e, principalmente, o papel da mediação dos alunos-pesquisadores-educadores. Essa mediação foi direcionada para a formação dos grupos partindo da idéia de que todo grupo tem um dinamismo tal que não se resume na realização de tarefas ou consecução de objetivos comuns. Estes funcionam mais como "convocante" do que como estruturante do grupo, isto é, a tarefa tem a função de reunir os indivíduos, mas não é suficiente para a estruturação grupal. Essa estruturação diz respeito a um processo dinâmico, vivenciado por todos na construção da identidade do grupo, que implica enfrentar conflitos e contradições.

Nesse sentido, o papel de mediador supera a idéia do educador como transmissor de conhecimentos e de normas de comportamentos adequados - inclusive do ponto de vista ambiental -, fundamentandose na idéia de que, se o ser humano caracteriza-se por sua ação transformadora na natureza, sendo assim produto da natureza, um ser natural - um ser natural humano -, então é no processo histórico que ele se faz. É a compreensão do sujeito individual como sujeito social, a idéia de indivíduo singular desenvolvida por Duarte (1993, p. 157):

Quanto menos desenvolvidas as relações entre os homens, menos possibilidade de individualização tem cada ser humano (...) o homem se 
torna mais individual e pode desenvolver uma atividade totalmente autônoma, necessariamente através de um grande desenvolvimento das relações sociais, da realidade humana objetivada e com a plena socialização do indivíduo.

A relação entre as pesquisadoras e as crianças pré-escolares foi construída cotidianamente, e as dificuldades com (in)disciplina, brigas e disputas entre as crianças foram um dos aspectos em que a inexperiência das alunas-pesquisadoras foi enfrentada pela forte relação afetiva que se estabeleceu. Observamos situação semelhante, mas com particularidades, nos Projetos desenvolvidos junto a estudantes das séries iniciais do ensino fundamental: pudemos observar a construção da relação entre todos os membros do grupo. (In)disciplina, brigas e disputas foram também muito presentes. A maior parte desses projetos aglutinou crianças de diferentes idades e foi importante observar que o grupo foi se consolidando como tal conforme as alunas-pesquisadoras foram assumindo seus papéis de mediadoras na busca, principalmente, da cooperação de todas as crianças no planejamento participativo para o levantamento dos dados e das ações desenvolvidas.

Nos Projetos com pré-adolescentes e adolescentes, a nãoformalidade do processo foi uma de suas características mais marcantes. Os grupos se constituíram de sujeitos que se conheciam previamente, mas que estavam em nova configuração, construindo novas relações individuais e coletivas. Um dos pontos mais importantes para análise do processo grupal aqui diz respeito às reconfigurações que os grupos sofreram em função da saída, periódica, de membros: ao completarem 14 anos, alguns estudantes saíram dos projetos para ingressar no mercado de trabalho. Trata-se de uma reconfiguração determinada por fatores externos ao grupo, mas que influencia o processo de construção de sua identidade, assim como está presente em todo processo, a ponto de exigir sua problematização nas discussões coletivas.

Nos projetos realizados com jovens do ensino médio, a diretividade no papel de mediador, relativizada pela proximidade da idade entre os parceiros do projeto, foi importante componente do processo grupal. Além disso, dois dos projetos, que aconteceram 
articulados entre si, iniciaram-se com um convite em escolas públicas e privadas, definindo um grupo, inicialmente com mais ou menos 20 jovens, cuja composição foi se modificando, no que diz respeito ao perfil socioeconômico dos participantes. Logo no início da realização do projeto, os alunos das escolas privadas saíram do mesmo, reconfigurando-o como exclusivo de alunos de escolas públicas. Isso nos mostra que não é a tarefa ou o objetivo comum que estrutura o grupo, mas a construção da identidade grupal a partir da formação de uma rede de identificações, determinadas pelos valores e referenciais sociais, políticos e culturais.

\section{Informação versus Formação: o papel dos temas ambientais.}

Nos Projetos realizados junto a crianças pré-escolares, os temas tratados foram: mapeamento ambiental ( 3 projetos), história infantil sobre temas ambientais ( 1 projeto) e mata ciliar (1 projeto). Os três projetos que tratam do mapeamento ambiental foram realizados na mesma EMEI em quatro diferentes salas por três alunas-pesquisadoras, num trabalho articulado, de orientação e discussão coletiva.

Com estudantes das séries iniciais do ensino fundamental, os temas geradores foram bastante variados: mapeamento ambiental, sensibilização ambiental, memória ambiental e diversidade do cerrado. Destaca-se aqui o fato de os projetos terem sido articulados dois a dois, isto é, os trabalhos com mapeamento ambiental e com sensibilização ambiental foram realizados com duas diferentes alunas-pesquisadoras, mas com o mesmo grupo de crianças e com reuniões realizadas no mesmo local, exigindo orientação e planejamento conjuntos. Os projetos sobre memória ambiental e diversidade do cerrado foram realizados também por duas alunas-pesquisadoras com o mesmo grupo de crianças e no mesmo local, com atividades em conjunto.

Dos cinco projetos realizados com pré-adolescentes e adolescentes, dois foram articulados entre si, os que tiveram como temas a distribuição e o consumo de água. Quanto aos outros, um deles tratou do tema "comportamento animal", outro, do "cerrado" e o outro, do "mapeamento ambiental". 
No ensino médio, os temas foram bem mais amplos, voltados, primeiramente, para a discussão do tema ambiental geral e a definição, posterior e coletiva, dos subtemas de interesse do grupo. Dois dos projetos, com duração de dois anos e articulados entre si, tinham como principal objetivo a organização de um grupo de jovens ambientalistas na cidade: o GAPMA (Grupo de Ação e Proteção ao Meio Ambiente). Esse Grupo identificou, através da proposta de mapeamento ambiental, pontos da cidade que indicavam problemas ambientais, segundo sua avaliação, e definiu, coletivamente, as ações ambientais realizadas, entre elas: um projeto de atuação em um "lixão"; um levantamento ambiental de uma área natural com uma proposta coletiva de trilha; uma exposição sobre a memória ambiental da cidade, entrevistando moradores, selecionando fotos antigas, que, expostas junto com as atuais, levaram a discussões sobre a degradação ambiental da cidade; uma distribuição de mudas, que proporcionou a oportunidade de discutir diretamente com as pessoas sobre a degradação do ambiente urbano; e, por último, a organização de uma Gincana da Natureza com a participação de mais de 1.500 estudantes de todas as escolas públicas da cidade. Dois outros Projetos com jovens do ensino médio realizaram-se em reuniões semanais, quando organizavam os dados coletados acerca das práticas sociais cotidianas de seus pares para refletir sobre essas práticas na perspectiva da sustentabilidade. Os hábitos e desejos de consumo identificados por esses jovens foram os principais temas dessas discussões.

O Projeto com idosos teve como tema o uso de plantas medicinais. O principal objetivo aqui foi produzir coletivamente conhecimentos para identificar as plantas medicinais mais utilizadas pelos participantes e pelas pessoas de suas relações pessoais. Essas práticas foram interpretadas com o apoio de conhecimentos científicos disponíveis e divulgadas através de uma exposição dos trabalhos do grupo e da construção de um Guia de Uso de Plantas Medicinais da região, produzido pela parceria entre o saber tradicional e o saber científico.

É importante destacar que todos os temas dos projetos, independentemente das especificidades, foram tratados a partir da idéia 
de que os processos educativos ambientais podem tomar diferentes temas como geradores da investigação na área de educação ambiental.

Vários projetos têm o mapeamento ambiental como ponto de partida, como tema gerador das investigações e discussões, fundamentando-se em Meyer (1991). A autora apresenta o mapeamento ambiental como uma proposta pedagógica que contribui para ampliar a compreensão dos educandos sobre o ambiente em que vivem. Essa proposta articula investigação e ação educativa, pois faz um levantamento ambiental, um diagnóstico do ambiente segundo a percepção dos envolvidos, que identificam o espaço social, histórico, político e cultural e, ao mesmo tempo, se apropriam do conhecimento produzido, isto é, são também sujeitos das ações educativas ambientais:

O mapeamento significa um inventário, um levantamento e um registro da situação ambiental do bairro e da cidade em seus múltiplos aspectos como: saneamento (água, esgoto e lixo), energia elétrica, transporte, tipo de moradia e materiais de construção, flora e fauna, recursos hídricos minerais, indústria e comércio, organização social do trabalho, serviço de saúde, patrimônio histórico, artístico e arquitetônico, áreas de lazer, agricultura, pecuária, hábitos alimentares e crenças. Enfim, inventariar as relações sociais que os seres humanos vão estabelecendo entre si e os demais seres vivos, quem se apropria e como se apropria dos elementos naturais (água. ar, terra, fogo), do céu, da flora e da fauna (MEYER, 1991, p. 16).

Além disso, essa proposta tem a plasticidade necessária para ser adaptada a diferentes grupos de sujeitos, com diferentes características sociais e históricas e qualquer faixa etária. Por ter como principal objetivo ampliar a compreensão dos sujeitos envolvidos acerca do ambiente em que vivem, pode ser realizada com resultados muito interessantes por crianças, jovens, adultos e idosos. Portanto, o mapeamento ambiental pode ser uma estratégia geradora de discussões dos temas socioambientais.

Do ponto de vista da produção de conhecimentos sobre o ambiente, os projetos realizados através do mapeamento ambiental mostraram seu potencial investigativo: crianças de diferentes faixas 
etárias construíram diferentes diagnósticos ambientais de seus bairros. Nos cinco projetos com essa proposta, as crianças desenharam e montaram maquetes do bairro ou da escola e seu entorno, identificando a dinâmica do ambiente, como também seus principais problemas: lixo nas ruas, falta de arborização, falta de espaços públicos de lazer, principalmente. A partir desse diagnóstico, em todos os projetos as crianças discutiram e realizaram as ações: em alguns deles, essas ações foram diretas no bairro, e em um deles a construção coletiva da "maquete" foi o objetivo, com a elaboração, por parte das próprias crianças, de um material didático a ser usado na escola. As ações realizadas no bairro, a partir do diagnóstico das crianças, foram: campanha junto à população para não jogar lixo nas ruas, articulada à reivindicação junto à Prefeitura e ao comércio do bairro para a colocação de lixeiras em pontos estratégicos do bairro, mutirão de limpeza da praça do bairro, etc.

Todas essas atividades foram sempre acompanhadas por estudos dos temas que surgiram no mapeamento, para que as crianças, se apropriando desses conhecimentos, pudessem desenvolver argumentos próprios em suas ações educativas ambientais. Em todos esses projetos, as crianças, adolescentes, jovens e idosos foram pesquisadores, educandos e educadores. Os participantes demonstraram muito interesse em realizar as ações ambientais discutidas coletivamente e sempre traziam para discussão de todo o grupo o que viam e percebiam no ambiente urbano. A qualidade da atuação grupal foi se transformando no transcorrer dos projetos: ao mesmo tempo em que os participantes se interessavam pelo ambiente e se reconheciam como parte dele, se percebiam também parte do grupo.

Alguns autores vêm contribuindo na compreensão dos temas ambientais como temas geradores de um processo educativo mais conseqüente para a educação ambiental. Layrargues (2001) analisa a proposta de Tbilisi para a educação ambiental no que diz respeito à resolução de problemas ambientais locais e conclui que, se articulada às propostas de participação social, engajamento, mobilização e emancipação, que compõem o conceito de educação ambiental crítica e transformadora, a resolução dos problemas locais deve ser um tema 
gerador e não uma atividade-fim nos projetos de educação ambiental. Esse mesmo autor discute os equívocos cometidos no uso da reciclagem do lixo como temática da educação ambiental, concluindo que enquanto a educação ambiental não problematizar criticamente seus temas não poderá ser considerada educação transformadora.

Loureiro (2004, p. 133) defende também a problematização dos temas ambientais como proposta pedagógica para a educação ambiental quando afirma:

Por outro lado, por mais que se admita a relevância pedagógica como etapa inicial do educar, não cabe ficar no plano da sensibilização, do reconhecimento do ambiente de vida, da ação no universo particular e de alterações de comportamentos individuais, como coisas válidas em si e suficientes para transformações societárias. É preciso articular a cotidianidade ao macrossocial, em uma atuação política que gere as transformações individuais e coletivas, simultaneamente, e a possibilidade de as experiências localizadas que foram bem-sucedidas se universalizarem.

Essas reflexões nos levam, do ponto de vista político-pedagógico, a retomar os "temas geradores" de Paulo Freire. Essa metodologia conscientizadora pode ser encontrada em várias de suas obras. Em Pedagogia do Oprimido (FREIRE, 1983), encontramos seus fundamentos filosófico-políticos: trata-se de uma proposta metodológica que só pode ser compreendida na perspectiva da educação libertadora, como um processo radical de conscientização dos homens no mundo. A partir do tema escolhido, o conjunto de educadores-educandos empreende, pelas discussões coletivas, problematizadoras, mediadoras das relações com o mundo e com os sujeitos, esforços de compreensão política das situações vividas.

\section{A construção da participação: um compromisso e um desafio}

Um dos mais importantes temas de análise que emergem dos projetos de pesquisa-ação participativa aqui analisados diz respeito ao grau e à configuração do processo de participação dos envolvidos. 
Entre essas condições sócio-históricas, determinantes do contexto, e do texto, na realização das propostas, destacam-se as diferenças de maturidade e autonomia dos sujeitos envolvidos no processo de investigação em curso. As crianças pequenas têm menos maturidade e menos autonomia do que outros grupos para delinear a produção de conhecimentos presente nessas propostas, mas podem, consideradas suas condições sócio-históricas, contribuir participativamente com a produção de conhecimentos sobre seu próprio processo educativo, sentido maior da pesquisa em educação ambiental.

Dessa forma, podemos avaliar que, com graus diferentes de participação - relacionados às suas condições concretas de vida e às condições concretas do desenvolvimento das propostas -, o exercício coletivo por parte dos sujeitos parceiros e dos(as) alunos(as) estagiários(as) como mediadores do processo participativo realizou-se em todas as propostas.

Com as crianças pequenas, pré-escolares, foi muito interessante observar suas condições de participação no delineamento das atividades do dia, na transformação do observado no mapeamento ambiental em tema gerador de estudos e discussões, na resolução dos conflitos que se estabeleciam nas relações entre elas. Entre as propostas desenvolvidas pelos pré-adolescentes e adolescentes, destaca-se a participação dos alunos no delineamento e realização da pesquisa sobre consumo e distribuição de água no bairro em que vivem: eles envolveram-se de tal forma com essa atividade - coletando contas de água no bairro para cálculos e análises de consumo, problematizando as razões dos moradores para o consumo de água e identificando os espaços comunitários para divulgação dos resultados dos estudos empreendidos - que elas resultaram em ações muito originais e produtivas junto à comunidade. No trabalho com o tema das plantas medicinais, as características do grupo configuraram um rico processo de aprendizagem de participação: tomar decisões coletivas sobre o que e como estudar e aprender foi destacado pelos participantes como a contribuição de maior importância para eles.

Vejamos, então, a participação como princípio metodológico dos trabalhos em análise. Brandão (1981) definiu a pesquisa participante 
como "uma modalidade nova de conhecimento coletivo do Mundo e das condições de vida de pessoas, grupos e classes populares" (p. 9). Demo (1989) define a pesquisa-ação como uma modalidade alternativa de pesquisa qualitativa com a tarefa de pesquisar e de participar, de investigar e educar articulando teoria e prática, afirmando que participação é conquista (DEMO, 2001). Ezpeleta \& Rockwell (1989) discutem a articulação entre a pesquisa e a participação como elementos centrais dessa metodologia, propondo que esses elementos estejam em permanente equilíbrio. Gómez et al. (1999) consideram conteúdo da participação o papel ativo que assumem os sujeitos no processo de investigação, os quais, partindo dos problemas reais, realizam reflexões rompendo com a dicotomia teoria/prática na produção de conhecimentos sobre os processos educativos. Brandão (1999) denomina como pesquisa participante aquela que se define pelo grau da participação dos sujeitos envolvidos. A participação dos envolvidos no processo de pesquisa também é problematizada por Thiollent (2000), que considera que essa metodologia tem como ponto de partida a articulação entre a produção de conhecimentos e o processo de conscientização para o enfrentamento de problemas sociais. A associação entre a produção de conhecimentos e a ação educativa é, para Brandão (2003), um amadurecimento da pesquisa para incorporarmos, de forma compartilhada, o saber, a ciência, a tecnologia e a educação na vida comunitária.

Com essas preocupações, compreendemos a pesquisa-ação participativa como uma modalidade de pesquisa que articula, radicalmente, ao processo de produção de conhecimentos em educação - e em educação ambiental - o agir educativo. Trata-se de um agir político, coletivo e democrático, compartilhado, um agir em parceria, portanto, também radicalmente participativo, emancipatório e transformador.

Para que possamos considerar como projetos de investigação científica os aqui analisados, é preciso identificar a produção de conhecimentos que eles proporcionam. Embora não mais importante do que a participação, a produção de conhecimentos também caracteriza essa metodologia. Assim, a pesquisa-ação participativa em 
educação ambiental exige participação na produção de conhecimentos ambientais e pedagógicos, pois tais categorias são fundamentais na área.

Os projetos analisados produziram conhecimentos sobre temas ambientais específicos, como os levantamentos ambientais e a história do bairro, identificando o cerrado como formação anterior à ocupação urbana, identificando espécies remanescentes do cerrado na área urbana em que vivem os participantes, identificando índices de consumo de água da população do bairro, hábitos de consumo dos participantes e das pessoas próximas, formas tradicionais de uso de plantas medicinais entre os participantes e seus pares, etc. Identificaram também formas mais adequadas de transmitir aos sujeitos que vivem no mesmo ambiente informações necessárias a um processo de conscientização ambiental comunitário, identificaram as estratégias didático-pedagógicas mais adequadas à aprendizagem significativa intrínseca das ações educativas ambientais, inclusive a lógica compreensiva, exigida na produção do material didático para a educação ambiental. Isso significa dizer que os projetos analisados contribuíram para a educação ambiental no que diz respeito à produção de conhecimentos sobre diferentes dimensões pedagógicas dos processos educativos ambientais que os alunos-pesquisadores viveram como educandos e como educadores tanto diretamente, nas decisões que tomaram e nas ações que desenvolveram, quanto indiretamente, ao revelarem, nas análises aprofundadas do que foi vivido, elementos ocultos dos processos pedagógicos para a educação ambiental.

\section{As crianças e a pesquisa-ação participativa: limites e possibilidades}

Entre os temas analisados, destaquemos, como conclusão, a participação de crianças em projetos de pesquisa-ação participativa em educação ambiental. A origem da pesquisa participante pode ser identificada na sociologia, antropologia e psicologia social, que, ao terem como "objeto" de pesquisa os estudos dos processos coletivos, perceberam nas metodologias participativas uma importante forma investigativa de articular relevância científica com relevância social nos 
processos de pesquisa. Vemos aqui, em geral, a identificação da pesquisa participativa com o mundo adulto.

Por outro lado, a pesquisa em educação ambiental na perspectiva aqui analisada tem mostrado a necessidade de produzir conhecimentos em algumas direções: mais do que conhecimentos sobre o ambiente, as formas sócio-históricas das relações que os seres humanos constroem sobre o ambiente e o campo do conhecimento pedagógico para a educação ambiental têm sido suas principais preocupações nessa produção.

Nesse sentido, as propostas de pesquisa-ação participativa com crianças, acompanhadas e vivenciadas nos trabalhos analisados neste estudo, revelam a possibilidade de construir conhecimentos sobre as relações desses sujeitos - pequenos, mas sujeitos - com o ambiente e sobre a pedagogia da educação ambiental, isto é, sobre como educar ambiental e criticamente as crianças. Nossos parceiros mirins produziram conhecimentos sobre seu próprio ambiente, conhecimentos sobre as estratégias educativas ambientais mais adequadas à sua comunidade, conhecimentos sobre as características pedagógicas mais adequadas ao material didático utilizado por eles próprios, etc. Os sujeitos participantes, parceiros na produção de conhecimentos para ações educativas ambientais que tenham a sustentabilidade e a emancipação como princípios educativos, nos mostraram como pensar e agir, ambiental e socialmente, de forma a contribuir para a construção de sociedades mais justas e equilibradas. Brandão (2003) nos ensina que a pesquisa participante vem mostrando-se muito diversa, mas o que a define é a possibilidade de dar aos diferentes grupos sociais o direito de produzir conhecimentos sobre eles próprios, e, nesse sentido, o autor escreve sobre a possibilidade da pesquisa participante com crianças:

...E não deveria, então, ser feito às próprias crianças? Se elas vivem o que através de incontáveis investigações imaginamos conhecer cientificamente, por que não perguntar a elas o que sabem sobre seu próprio modo de vida? Por que não dialogar com e entre elas sobre o que vivem e o que desejam, antes de investigá-las ou de realizar "experimentos" sobre elas. Por que não aprender a viver pesquisas com elas em vez de apenas realizar investigações 
experimentais sobre elas? Romântico? O que pensar, porém, do longo tempo em que as mulheres não podiam (ou não deviam) realizar estudos sobre o corpo, a vida e a própria identidade? (BRANDÃO, 2003, p. 16).

As crianças, parceiras na produção de conhecimentos sobre educação ambiental, nos ensinaram também que, juntos, podemos construir a formação inicial de nossos alunos como educadores ambientais num projeto de superação da crise de legitimidade da universidade pela possibilidade de vivenciarmos uma formação que articule ensino, pesquisa e extensão, contribuindo para a construção de uma proposta de universidade pública, democrática, competente e de qualidade. Esses são nossos compromissos e desafios, nossos desejos de continuar...

\section{Referências bibliográficas}

BRANDÃO, Carlos R. A pesquisa participante. São Paulo: Brasiliense, 1981. . Repensando a pesquisa participante. $3^{\mathrm{a}}$ ed. São Paulo: Brasiliense, 1999. - A pergunta a várias mãos: a experiência da pesquisa no trabalho do educador. São Paulo: Cortez, 2003.

BRÜGGER, Paula. Educação on adestramento ambiental? Florianópolis: Letras Contemporâneas, 1994.

BUARQUE, Cristovam. A aventura da universidade. São Paulo: Paz e Terra e Edunesp, 1994.

DEMO, Pedro. Metodologia científica em ciências sociais. 2. ed. São Paulo: Altas, 1989. Participação é Conquista. $5^{\text {a }}$ ed. São Paulo: Cortez, 2001.

DUARTE, Newton. A individualidade para si: contribuição a uma teoria histórico-social da formação do indivíduo. Campinas: Autores Associados, 1993. 
EZPELETA, Justa; ROCKWELL, Elsie. Pesquisa Participante. $2^{\mathrm{a}}$ ed. São Paulo: Cortez e Autores Associados, 1989.

FREIRE, Paulo. Pedagogia do Oprimido. São Paulo: Paz e Terra, 1983.

GÓMEZ, Gregorio Rodríguez.; FLORES, Javier Gil.; JIMÉNEZ, Eduardo García. Metodología de la investigación cualitativa. Málaga: Ediciones Aljibe, 1999.

LAYRARGUES, Philippe Pomier. A resolução de problemas ambientais locais deve ser um tema gerador ou a atividade-fim da educação ambiental? In: REIGOTA, Marcos (org.). Verde Cotidiano: o meio ambiente em discussão. Rio de Janeiro: DP\&A, 2001.

O cinismo da reciclagem: o significado ideológico da reciclagem da lata de alumínio. In: LOUREIRO, Carlos Frederico B; LAYRARGUES, Philippe Pomier; CASTRO, Ronaldo Souza de (org.). Educação Ambiental: repensando o espaço da cidadania. São Paulo: Cortez, 2002.

LEFF, Enrique. Saber Ambiental: sustentabilidade, racionalidade, complexidade, poder. $2^{\mathrm{a}}$ ed. Petrópolis: Vozes, 2001.

LOUREIRO, Carlos Frederico B. Trajetória e Fundamentos da Educação Ambiental. São Paulo: Cortez, 2004.

MEYER, Mônica. Educação ambiental: uma proposta pedagógica. Em aberto, Brasília, v.10, n.49, p. 40-45, jan-mar. 1991.

SANTOS, Boaventura de Sousa. Introdução a uma ciência pós-moderna. Rio de Janeiro: Graal, 1989.

SAVIANI, Dermeval. A pedagogia histórico-critica: primeiras aproximações. Campinas: Autores Associados, 1994.

THIOLLENT, Michel. Metodologia da pesquisa-ação. 10a ed. São Paulo: Cortez, 2000. 
